\title{
Design, simulation and testing of an array of nano electro mechanical switches (NEMS)
}

\author{
Luay Mahdi, Qais Al-Gayem
}

Department of Electrical Engineering, Babylon University, Iraq

\begin{tabular}{|c|c|}
\hline Article Info & ABSTRACT \\
\hline Article history: & \multirow{10}{*}{$\begin{array}{l}\text { Electro mechanical switches used for multi-purposs applications with ultra } \\
\text { small size in nano meter scale, operating in very small voltage in millivolts, } \\
\text { approximately zero leakage current due to air gap separation between } \\
\text { electrodes with three terminals that easy to control it. Nano electro } \\
\text { mechanical switches are electronic switches similar to those used by } \\
\text { conventional semiconductor switches in application as they can be used as } \\
\text { relays, logic devices. The basic principle of nano electro mechanical switches } \\
\text { is electronic switches operation is fundamentally different from } \\
\text { semiconductor switches. They have many advantages over conventional } \\
\text { semiconductor switches such as low-power digital logic applications, ability } \\
\text { to work with very small voltage signals for low dynamic energy } \\
\text { consumption, and durability against hostile environments such as high } \\
\text { temperatures and radiation contaminated spaces. In this article, we will } \\
\text { design, implement, and test a matrix of nano electro mechanical switches by } \\
\text { on line test using the superposition theory. The simulations of these switches } \\
\text { were implemented using the MATLAB-Simulink and ORCAD Pspice } \\
\text { environments. Also, controlling the flow of current was achieved by means } \\
\text { of a nanometer movement to make or break the physical contact between the } \\
\text { electrodes. }\end{array}$} \\
\hline Received Jul 11, 2020 & \\
\hline Revised Dec 5, 2020 & \\
\hline Accepted Jan 5, 2021 & \\
\hline Keywords: & \\
\hline CMOS & \\
\hline NEMS & \\
\hline ORCAD & \\
\hline Semiconductor & \\
\hline VLSI & \\
\hline
\end{tabular}

This is an open access article under the CC BY-SA license.

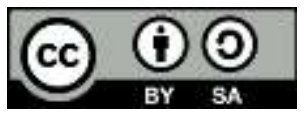

\section{Corresponding Author:}

Luay Mahdi

Department of Electrical Engineering

Babylon University, Najaf road, Babylon, Iraq

Email: luaymahdi1976@gmail.com

\section{INTRODUCTION}

Nano electro mechanical switches (NEMS) are switching devices have been investigated in logic application [1-3]. NEMS switches with its almost ideal switching, based on their promising characteristics, the air gap separation between electrodes leads to virtually zero leakage current when inactive, sharp ONOFF transition and infinitely steep sub-threshold slope, these properties are being explored to consider it as a better candidate for executing digital circuits. In [4-7], NEMS switches are modeled in a circuit simulation ambience by enhancement an electrical corresponding spice model for the electrical behaviors of the NEMS switch.

A. Haider et al. [8], in this study they using field programmable gate array (FPGAs) they made group of gates as MEMS switches and improve the energy efficient of the switch.C. Fred et al. [9], they design and calculate the four terminal nano electro mechanical relay in very large scale integration (VLSI). F. Hamed et al. [10], they study the properties of material when they down scaling in nano meter and their impact on the electrical and mechanical action. Sijing Han et al. [11], they designed NEM switch by utilizaing COMSOL multi physics that used to excuteing computational and sequential circuits.K. Alzoubi et al. [12], they used CMOS technology in nano scale to construct logic and sequential circuit. Ming Yin et al. 
[13], submitted new design for (NEMS) based (LC) oscillation circuit utilized to inspect very small frequency vibration.W. Merlijn et al. [14], offer overview discussed the affacts that facing the (NEMS) such as creep, stiction, wear, fatigue and packaging as reliability concering for these devices. The problems that referred by the previous studies to designing and implementing nano systems were theoretical studies, did not address programmatically simulating these systems in addition to that they did not address improving energy efficiency in those systems where the power is improved by reducing the leakage current and the supplied voltage due to the special construction of these switches.

\section{PRINCIPLE OPERATION OF NEMS}

The simple shape of an electro mechanical switches is construct from two electrodes movable and fixed with air gap separate between them as shown in Figure 1, which illustrate this switch in OFF and ON state, electromechanical switches are operated when the movable part moves toward the fixed part under the impact of the electrostatic force [15]. This force is produced after applying voltage difference between two parallel electrodes and by controlling the voltage, the switch becomes in the ON state or OFF state. This is called the electrostatic actuation principle. Applying a potential difference between the electrodes of switch (fixed and movable), this makes one of them attracted towards the other and thus. If electrostatic force overcome the elastic force of movable part at this time, switch electrodes become on contact [16].

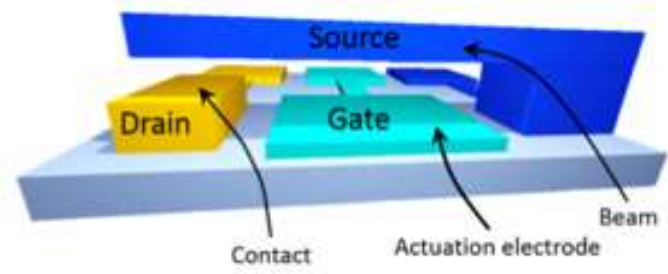

(a)

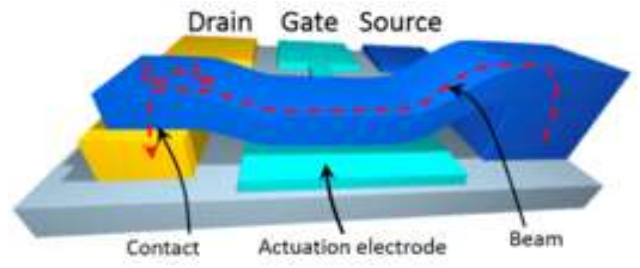

(b)

Figure 1. Illustration of an electrostatic 3T relay, (a) as fabricated, (b) actuated into the ON state

The movable part is hanging by a spring as shown in Figure 2.b, so it has an elastic constant $\mathrm{k}$ generating spring force $F_{\text {spring }}$. The magnitude of spring force is increment linearly with displacement that witch calculate as shown in (1), while electrostatic force $F_{\text {elec }}$ is inversely proportional with displacement. Thus, electrostatic force rise super-linearly by reducing displacement as evaluate using as shown in (2) and, $F_{\text {elec }}$ is always bigger than $F_{\text {spring }}$ [17-20].

$$
\begin{aligned}
& F_{\text {Spring }}=K \Delta G=K\left(G_{0}-G\right) \\
& F_{\text {elec }}=\frac{\varepsilon_{o} A_{\mathrm{o}} V_{g b}^{2}}{2\left(g_{\circ}-Z\right)^{2}}
\end{aligned}
$$

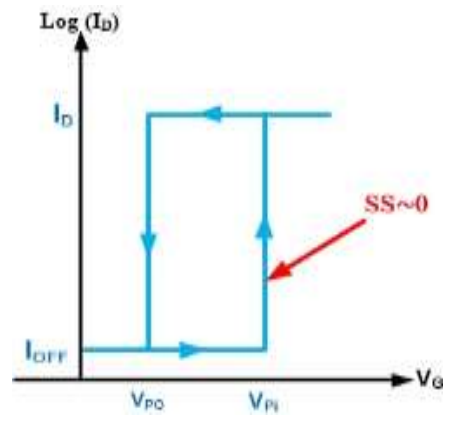

(a)

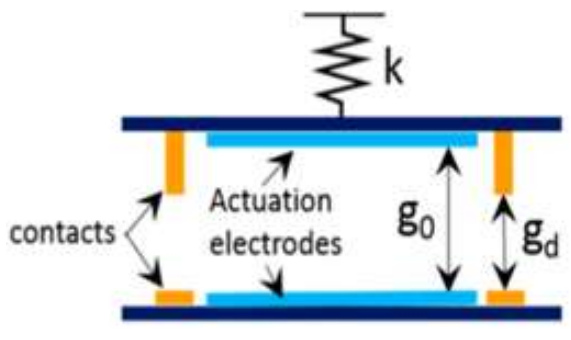

(b)

Figure 2. (a) Electrical characteristics of a nano-electro-mechanical (NEM) switch, (b) Spring model of a NEM switch 


\section{MEMS/NEMS PHYSICS ACTUATION PRINCIPLES}

MEMS/NEMS can perform its functions due to different physical actuation principles. These operational principles include: quantum mechanics, Maxwell's equations, electrostatics, first and second laws of thermodynamics, and Schrödinger's equation. The conventional electromechanical systems and MEMS are operated using identical operational principles and foundations while NEMS are operated by utilizing different conceptions and theories. Indeed, the designer uses the classical lagrangian and electromagnetics (Maxwell's equations) as well as Newtonian mechanics to study MEMS and conventional electromechanical systems. On the other hand, NEMS are designed by using quantum theory and nano electro mechanical conceptions [21-24].

\section{TYPE OF CONTACT IN NEMS SWITCHES}

There are two types of contact in NEMS switches:

- Metal-metal contact (Ohmic switch)

- Metal-dielectric contact (Capacitive switch)

In these two types of (NEMS) switches, the switch is opened when the elastic force of the movable part overcomes the electrostatic force after the voltage difference between the switch's electrodes is reduced to specific limit. Electro mechanical switches are much more attractive than other types of actuation mechanical switches because of low power consumption, high-speed transfer from ON state to OFF state and vice versa and easy to integrate with other circuit elements to make hybrid systems uses in special applications. All these features make this type of switches more desirable when compared with other types of mechanical switches [25].

\section{DESIGN AND SIMULATION OF NANO ELECTRO MECHANICAL SWITCH}

In this paper there are two categories of design and simulation for Nano electromechanical switches was offered to explain the operation process.

\subsection{Single nano electro mechanical switches (NEMS)}

In micro electro mechanical switches (MEMs) the effects of van der waals forces is so small and can be ignored when changing the physical properties, while in nano electro mechanical switches (NEMS) it has great effects and it is imposible to neglect it. The van der Waals forces can be calculated as shown in (3) [2627].

$$
F_{v d w}=\frac{H A}{6 \pi\left(g_{o}-Z\right)^{3}}
$$

There are another force must be calculated to construct the structure of nano electro mechanical switch called damping force as shown in (4) [24].

$$
D=\sqrt{\frac{k * m}{Q}}
$$

These four forces (electrostatic force, spring force, van der waals force and damping force) are summed together by using adder. The product out of the adder is dividing by the mass to convert it to an equivalent acceleration, this step called (modulation step) then, the acceleration signal must be convert to produce velocity by integrate the acceleration signal for the first integrator, the quantity out of the first integrator will be integrated for second time by the second integrator to produce displacement (u). The next step is to get an actuation gap thickness $(\mathrm{g})$ by subtracting the displacement $(\mathrm{u})$ from the gap displacement $\left(g_{0}\right),\left(g=g_{0}-\mathrm{u}\right)$. To produce the response of nano switch we must evaluate the value of capacitance between two electrodes by using the actuation gap thickness that calculated previously. The last step is that the output signal should be pass through second order (high pass filter) using (Butterworth) filter with cutoff frequency of (100) HZ is prepared to reproduce input signal. The waveform of output signal that evidence on the oscilloscope screen describe if the switch runs without faults or not. MATLAB/Simulink program is the circuit simulation model used to design nano electro mechanical switch as shown in Figure 3. This design including bias superposition technique and the effect of van der walls force because dimensions of this electro mechanical switch in nano scale ( $4.5 \mathrm{~nm}$ thickness). 


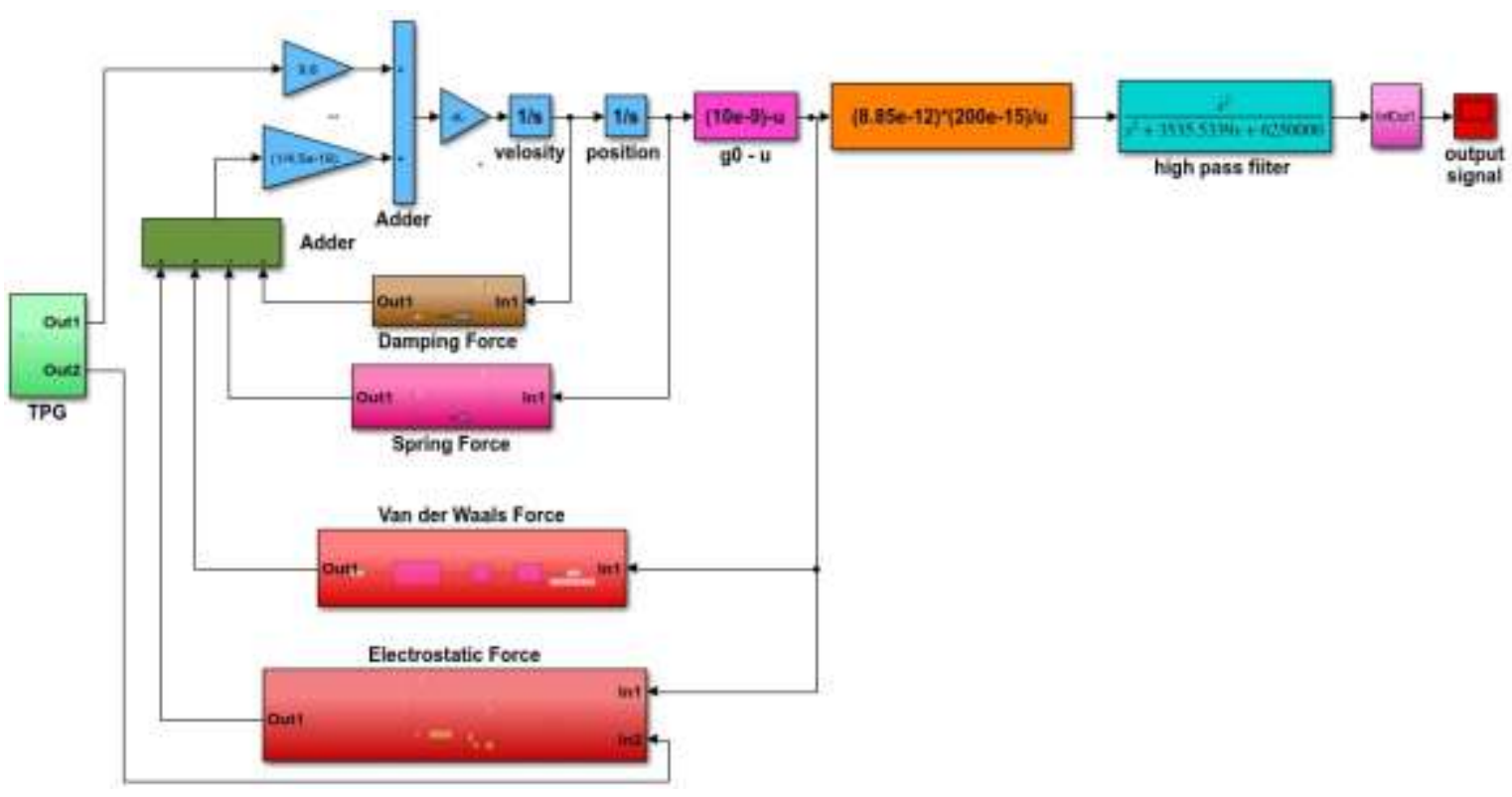

Figure 3. MATLAB-simulink of nano electro mechanical switch including bais superposition

The supplied signals parameters to simulate this circuit is explained:

a) Carrier signal is the square waveform signal with amplitude voltage of (1.5) volts, the duty cycle is about (70\%), (10 HZ) operating frequency, this signal must be converting to an acceleration signal by multiplied these voltages by 9.81 . Where the waveform of supply signal before amplification is shown in Figure 4.

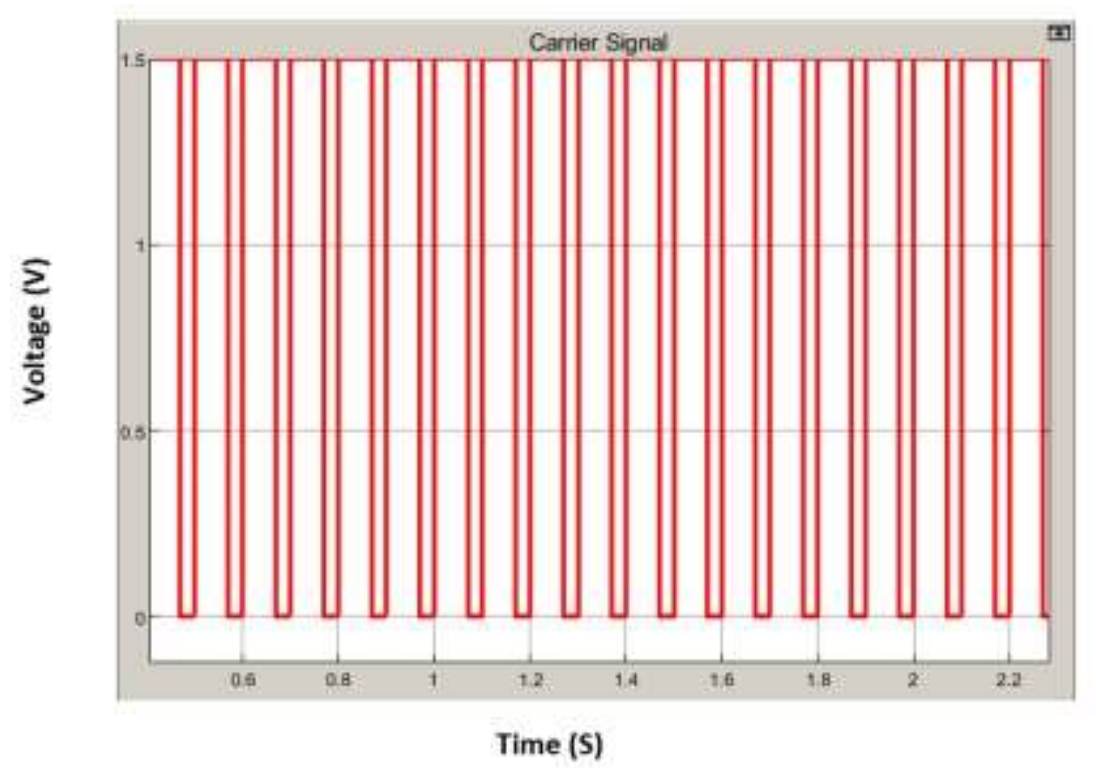

Figure 4. Waveform of carrier signal

b) Testing signal is the square waveform with amplitude voltage of (1) volts, the duty cycle is about (50\%), (100 HZ) operating frequency. This inspection signal is modulated with carrier signal as shown in Figure 5. The checking operation via bias superposition is utilized when the check signal is applied in the structure of nano switch in order to inspect if nano switch runs normally and the results is accuracy or not as a result of some type of faults. 


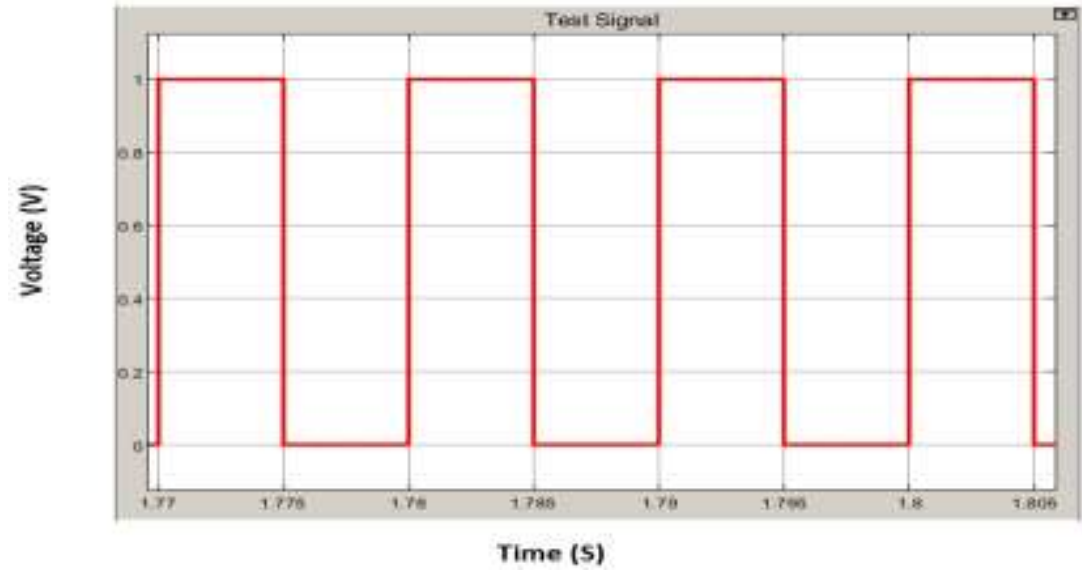

Figure 5. The waveform of test signal

\subsection{Array of nano electro mechanical switches (Array NEMS)}

In this case we use an $(3 * 3)$ array of nano electro mechanical switches as shown in Figure 6 , it will be noted that any of these nine switches have the same parameters of the switch in the first case above. The control circuit used to arrange the manner of testing for each switch in the array by testing each row or each column or it can test randomly this self-test technique has been appointed to analyse the output of switch to check if the switch is faulty or fault free.

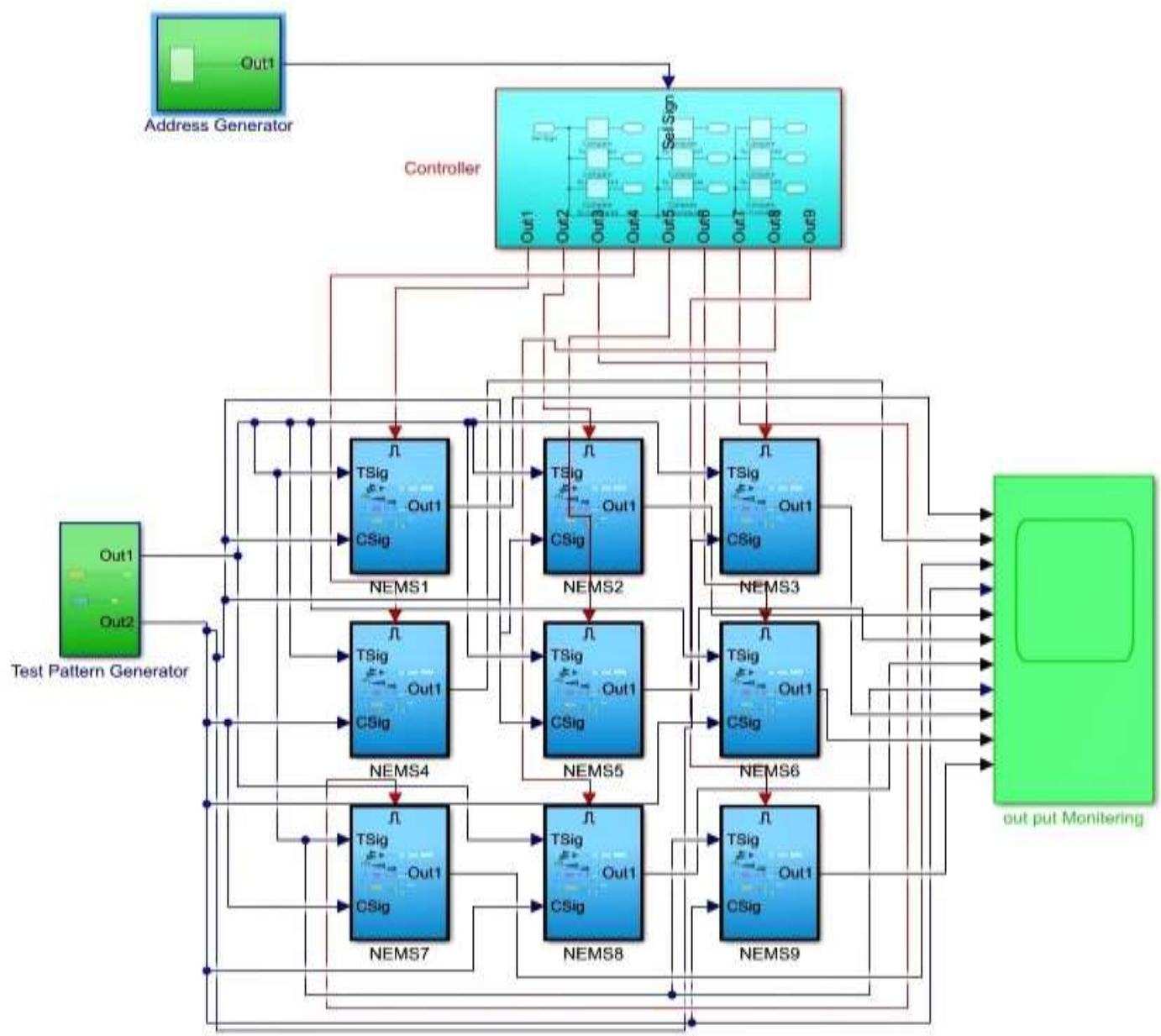

Figure 6. MATLAB-simulink of $(3 * 3)$ array of a Nano-Electro-Mechanical switch (NEM) 


\section{Faults of nano electro mechanical switches}

The reliability concerns that govern the life of (NEMS) should be carefully considered when designing and manufacturing these switches. The Table 1 shows the failure mechanisms and their impact on the devices parameters.

Table 1. NEMS failure mechanisms and their impact on the devices parameters

\begin{tabular}{|c|c|c|}
\hline Failure & Reasons & Effects \\
\hline Creep & $\begin{array}{l}\text { Applied stress, intrinsic stress and thermal } \\
\text { stress. }\end{array}$ & Has an impact on the in young modules $E$. \\
\hline Wear & Adhesive, abrasive and corrosive. & $\begin{array}{l}\text { Has an impact on damping factor } D \text {, effective } \\
\text { mass } m_{\text {eff }} \text { and changes the value of pill-in } \\
\text { voltage. }\end{array}$ \\
\hline Fatigue & $\begin{array}{l}\text { Brittle fatigue, this type of fatigue occurs when } \\
\text { cyclically varying applied stress that necessary } \\
\text { to occurs the crack growth or static fatigue, this } \\
\text { type of fatigue when a cyclically changing } \\
\text { applied stress is not required to occur the crack } \\
\text { growth. }\end{array}$ & $\begin{array}{l}\text { Has an impact on changing the value of pull in } \\
\text { voltage because it may affect the stiffness } \\
k \text { and damper factor } D \text {. }\end{array}$ \\
\hline Fracture & Excessive load fracture, or fatigue fracture. & $\begin{array}{l}\text { Has an impact on changing the dimensions of } \\
\text { devices that will changes the overall area and } \\
\text { output voltage. }\end{array}$ \\
\hline Crack & $\begin{array}{c}\text { Happens in beam of device decreases its } \\
\text { stiffness. }\end{array}$ & $\begin{array}{l}\text { Has an impact on decreasing the resonance } \\
\text { frequency. }\end{array}$ \\
\hline
\end{tabular}

\section{NANO SWITCH SIMULATION TEST RESULTS}

\subsection{Single nano electro mechanical switch}

This type of nano electro mechanical switch was supplied with testing and carrier signal.waveform as shown in figure 4 \& figure 5 respectively, where the applied signal to this type is square wave with $1.5 \mathrm{~V}$ peak amplitude for $70 \%$ of the cycle that makes the switch in case of (ON mode), and $0 \mathrm{~V}$ for $30 \%$ of the cycle that makes the switch in case of (OFF mode). The output signal gets from results is seen on the display of the oscilloscope result in two limits (1) V the high level is referring to the (ON mode), while near to zero is the low level is referring to (OFF mode) as shown in figure 7. This effect is spotted when the nano switch works without any faults. It should be noted that in previous studies, it did not mention simulations for NEMS system.

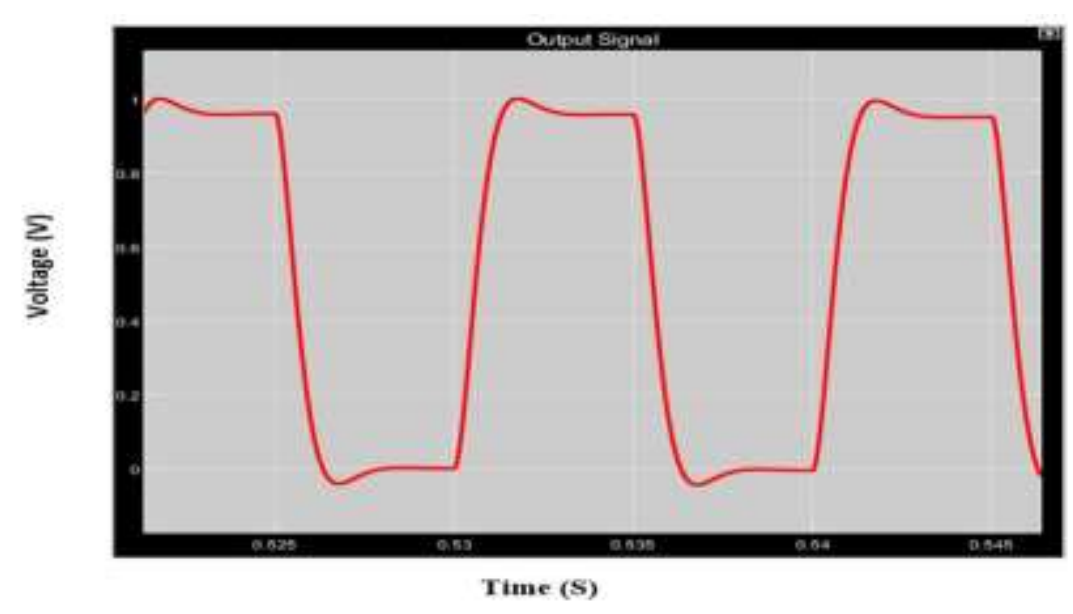

Figure 7. The output signal when the switch work without any defect

\subsection{Array of nano electro mechanical switches}

The results in this case are similar to the results that we get in case one but, in this case, we have a nine switch arrange in matrix as explained in Figure 6. This technique is based on applying test signal for any switch in this matrix and using control circuit to arrange the manner of test for each switch in the array, this self-test technology has been utilized to analyze the output of switches to inspect if the switch is run properly 
or in failure mode, while the first simulation results are shown in Figure 8. The design and simulation of a matrix of nano electro mechanical switches is considered a modern and sophisticated study where the results were ideal from design and examination and thus it became possible to implement or fabricate these nano switches in practice. The testing time required to inspect of $(3 * 3)$ array of nano electro mechanical switches is 1 second which is equal to the spending time for testing single nano electro mechanical switch.

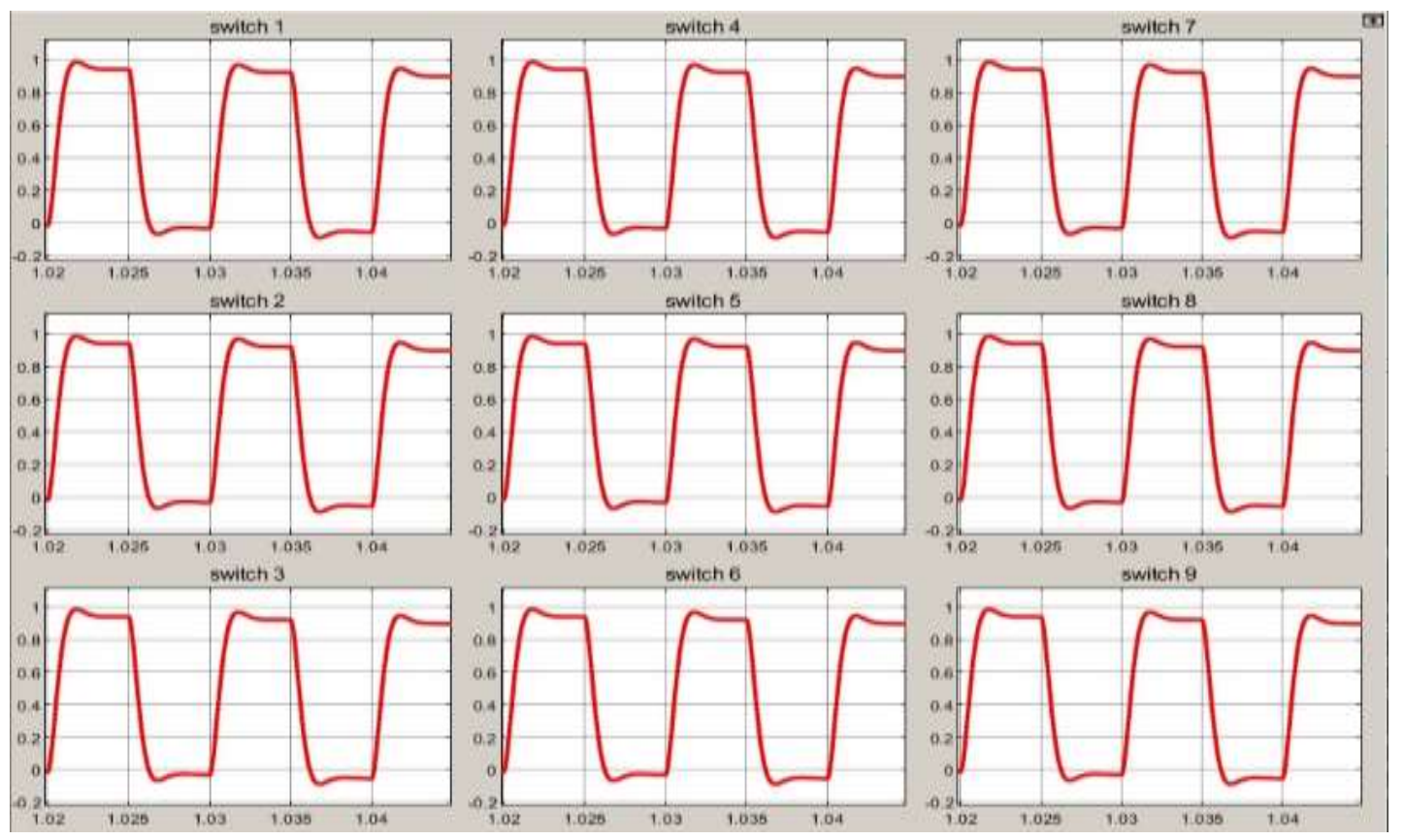

Figure 8 . Waveform of t output signal for $(3 * 3)$ array of nano electro mechanical (NEM) switch

\section{CONCOLUSION AND FUTURE WORK}

In this paper, a novel model for nano electro mechanical switch was designed, simulated and tested. This design achieved that this nano electro mechanical switch is consider as a better nominee nano-switch for producing the efficient power to overcome drawbacks in (nano-meter) technology. This design used to construct an array of nano electronmechanical switches which can be testing by an embedded testing circuit to reduce testing time with high testing area overhead, low cost and small footprint chip, this technology has been also utilized in nano applications for switch matrix, control unit, monitoring unit and process unit of signals are using together with this technology to obtain self-observation strategy at the system level where the faulty switches can be separated. Future work in the next study they improve the power conception and speed, time of the switching.

\section{REFERENCES}

[1] H. Kam, T. J. K. Liu, V. Stojanovic, D. Markovic, and E. Alon, "Design, optimization, and scaling of MEM relays for ultra-low-power digital logic,” IEEE Trans. Electron Devices, vol. 58, no. 1, pp. 236-249, Jan. 2011, doi: 10.1109/TED.2010.2082545.

[2] R. Nathanael, V. Pott, H. Kam, J. Jeon, and T.-J. K. Liu, "4-terminal relay technology for complementary logic," IEDM Tech. Dig., pp. 1-4, Dec. 2009, doi: 10.1109/IEDM.2009.5424383.

[3] N. Sinha, T. S. Jones, Z. Guo, and G. Piazza, "Body-biased complementary logic implemented using AlN piezoelectric MEMS switches," Journal of Microelectromechanical Systems, vol. 21, no. 2, pp. $484-49$ Apr. 2012, doi: 10.1109/IEDM.2009.5424215.

[4] K. Akarvardar, et al., "Design considerations for complementary nanoelectromechanical logic gates," IEDM Tech. Dig., pp. 299-302, Dec. 2007, doi: 10.1109/IEDM.2007.4418930.

[5] K. Alzoubi, D. G. Saab, S. Han, and M. Tabib-Azar, "Complementary nano- electro-mechanical switch for ultralow-power applications: Design and modeling,” Proc. 12th Int. Symp. Quality Electron. Design (ISQED), Mar. 2011, pp. 1-8, doi: 10.1109/ISQED.2011. 5770810.

[6] M. Spencer, et al., "Demonstration of integrated micro-electromechanical switch circuits for VLSI applications," IEEE J. Solid-State Circuits, vol. 46, no. 1, pp. 308-320, 2010, doi: 10.1109/ISSCC.2010. 5434010. 
[7] I. Chen, et al., "Scaled micro-relay structure with low strain gradient for reduced operating voltage," ECS Trans., vol. 45, no. 6, pp. 101-106, 2012, doi: 10.1149/1.3700943.

[8] A. Haider, M. Andrey, and Y. Alex, “A scalable physical model for Nano-Electro-Mechanical relays," IEEE, 24th International Workshop on Power and Timing Modeling, Optimization and Simulation (PATMOS), 2014.

[9] C. Fred, K. Hei, M. Dejan, Tsu-Jae King Liu, S. Vladimir and A. Elad, "Integrated circuit design with NEM relays," IEEE, pp.1-8, 2007.

[10] F. Hamed, F. Dadgour , M. Muhammad, C. Alan, S. Navab and B. Kaustav, "Impact of scaling on the performance and reliability degradation of metal-contacts in NEMS devices," IEEE, 2011.

[11] Sijing Han, "Design and Modeling environment for Nano- electro- mechanical switch (NEMS) digital systems," PH.D. Thesis, Case Western Reserve university, 2013.

[12] K. Alzoubi, D. Saab, S. Han and M.. Azar, "Complementary Nano-Electro-Mechanical Switch for ultra-low-power applications design and modeling," 2011 12th International Symposium on Quality Electronic Design, Mar. 2011.

[13] Ming Yin, Cangran Guo, Zewen Liu and Yingjiang Zhao, "Design of a NEMS based LC oscillation circuit for tiny vibration determination," 2011 International Conference on Electric Information and Control Engineering, Apr. 2011.

[14] W. Merlijn and S. Van, "MEMS Reliability from a failure mechanisms perspective," Microelectronics Reliability, pergamon, vol. 43, no.7, pp. 1049-1060, Jul. 2003, doi: 10.1016/S0026-2714.

[15] Peschot, A., Qian, C., \& Liu, T.-J. (2015). Nanoelectromechanical Switches for Low-Power Digital Computing. Micromachines, 6(8), 1046-1065.Hisamoto, et al., "A self-aligned double-gate MOSFET scalable to," IEEE Trans Electron Devices, vol. 47, pp. 2320-2325, 2000.

[16] F. Chen, H. Kam, D. Markovic, T. J. King, V. Stojanovic, and E. Alon, "Integrated circuit design with NEM relays", International Conference on Computer-Aided Design, Nov. 2008, pp.750-757.

[17] G. M. Rebeiz, et al., "The search for a reliable MEMS switch?,” IEEE Microw. Mag, vol. 14, pp. 57-67, 2013.

[18] A. Peschot, C. Qian, "Nano Electro Mechanical Switches for low-power digital computing," Micromachines, vol. 6, no. 8, pp. 1046-1065, Aug. 2015.

[19] Jin Woo Lee, Ryan Tung, Arvind Raman, Hartono Sumali and John P Sullivan, "Squeeze-film damping of flexible micro cantilevers at low ambient pressures: theory and experiment," Journal of Micromechanics and Micro Engineering, 2009.

[20] Sazzadur Chowdhury, M. Ahmadi, W. C. Miller, "A comparison of pull- in voltage calculation methods for memsbased electrostatic actuator design," International Conference on Sensing Technology, 2005.

[21] K. L. Tsu-Jae, J. Jaeseok, N. Rhesa, K. Hei, P. Vincent, and A. Elad, "Prospects for MEM logic switch technology," 2010 International Electron Devices Meeting, Dec. 2010.

[22] P. Vincent, N. Rhesa, and A. Elad, "Mechanical computing redux: relays for integrated circuit applications," Proceedings of the IEEE, vol. 98, no.12, pp. 2076-2094, Jan. 2011.

[23] H. Cai, G. Ding, Z. Yang, Z.. Su, J. Zhou and H. Wang, "Design, simulation and fabrication of a novel contactenhanced MEMS inertial switch with a movable contact point," Journal of Micromechanics and Micro engineering, 2008.

[24] F. Jacob, "Handbook of modern sensors physics, designs, and applications," Fourth Edition, Springer Science business Media, 2016.

[25] S. E. Lyshevski, "Nano and microelectromechanical systems: fundamentals of nano and micro engineering," Handbook, Library of Congress Cataloging-in-Publication Data, Boca Raton, 2001.

[26] U. Dincer and W. Avik, "Sub Thermal Switching with Nano mechanical Relays," University of Virginia, Charlottesville, pp.1-8, Jun. 2015.

[27] P. Faraday, “An Introduction to MEMS,” School of Mechanical and Manufacturing Engineering, pp. 1-16, 2002. 